The University of San Francisco

USF Scholarship: a digital repository @ Gleeson Library | Geschke Center

Nursing and Health Professions Faculty Research and Publications

6-14-2014

\title{
Hospital Staff Registered Nurses' Perception of Horizontal Violence, Peer Relationships, and the Quality and Safety of Patient Care
}

Christina Purpora

University of San Francisco, cmpurpora@usfca.edu

M.A. Blegen

N.A. Stotts

Follow this and additional works at: http://repository.usfca.edu/nursing_fac

Part of the Nursing Commons

\section{Recommended Citation}

Purpora, Christina; Blegen, M. A.; and Stotts, N. A., "Hospital Staff Registered Nurses' Perception of Horizontal Violence, Peer Relationships, and the Quality and Safety of Patient Care" (2014). Nursing and Health Professions Faculty Research and Publications. Paper 70.

http://repository.usfca.edu/nursing_fac/70

This Article is brought to you for free and open access by the School of Nursing and Health Professions at USF Scholarship: a digital repository @ Gleeson Library | Geschke Center. It has been accepted for inclusion in Nursing and Health Professions Faculty Research and Publications by an authorized administrator of USF Scholarship: a digital repository @ Gleeson Library | Geschke Center. For more information, please contact repository@usfca.edu. 


\title{
Title:
}

Hospital Staff Registered Nurses' Perception of Horizontal Violence, Peer Relationships, and the Quality and Safety of Patient Care

\begin{abstract}
Objective: To test hypotheses from a horizontal violence and quality and safety of patient care model: horizontal violence (negative behavior among peers) is inversely related to peer relations, quality of care and it is positively related to errors and adverse events. Additionally, the association between horizontal violence, peer relations, quality of care, errors and adverse events, and nurse and work characteristics were determined.

Participants: A random sample $(\mathrm{n}=175)$ of hospital staff Registered Nurses working in California.

Methods: Nurses participated via survey. Bivariate and multivariate analyses tested the study hypotheses.
\end{abstract}

Results: Hypotheses were supported. Horizontal violence was inversely related to peer relations and quality of care, and positively related to errors and adverse events. Including peer relations in the analyses altered the relationship between horizontal violence and quality of care but not between horizontal violence, errors and adverse events. Nurse and hospital characteristics were not related to other variables. Clinical area contributed significantly in predicting the quality of care, errors and adverse events but not peer relationships.

Conclusions: Horizontal violence affects peer relationships and the quality and safety of patient care as perceived by participating nurses. Supportive peer relationships are important to mitigate the impact of horizontal violence on quality of care.

Key words: peer, negative workplace behavior, peer communication. 


\section{Introduction}

Negative behavior such as use of sarcasm or intimidation occurs among workers in nonhealthcare as well as health care industries $[11,18,22,39]$. Healthcare researchers identified negative behavior at work among medical residents in the United States (US) [5] and the United Kingdom (UK) [27]; nurses in Australia, New Zealand, the UK and the US [12, 21, 26, 33]; and across these disciplines in the US [31].

Negative behavior among persons of equal status (e.g. hospital staff nurses) is called horizontal violence [6]. Horizontal violence results in psychological harm, job dissatisfaction, and strained peer relationships [21, 24, 32]. Horizontal violence is more hurtful and the source of greater anguish than when doctors or patients inflict similar behaviors on nurses [12, 24, 34]. Horizontal violence has prompted some nurses to contemplate leaving their job or nursing, a consequence for the profession and the institutions where they work [17, 24, 33, 35, 38]. Others suggest that horizontal violence jeopardizes patient safety and lessens the quality of patient care $[21,24,32]$. While this review suggests that nurses, nursing, healthcare organizations, and possibly patients suffer consequences as a result of horizontal violence, not enough is known about how horizontal violence and its consequences for nurses are related to the quality and safety of patient care. To add to our knowledge about the effects of horizontal violence among nurses in hospitals, the purpose of this study was to describe the relationships among horizontal violence, peer relationships, and the quality and safety of care.

\section{Conceptual Framework}

A horizontal violence and quality and safety of patient care model guided this study (see figure 1) $[24,25]$. The concepts of horizontal violence, peer relationships (communication), and the quality and safety of care were the focus of the analysis. The term horizontal violence 
originates in oppression theory [13] and signifies negative behavior among peers that exhibits lack of respect and wounds the dignity of the receiver [6]. The notion that nurses are oppressed, or dominated by others, and thus at risk for horizontal violence is not new $[4,29,30]$. Hospitals are hierarchical institutions influenced by a multitude of forces and nurses have less power in them than physicians and administrators [14]. Practicing in such a socially constructed environment may aggravate nurses who encounter barriers when they advocate for patients and their practice [8]. They may feel frustrated by factors in their work environment over which they have no control including short patient stays and multiple demands on their time [16]. Given the assumption they are oppressed, they may release their increasing frustration through horizontal violence rather than direct it toward those at higher levels of the hierarchy $[24,30]$. Peer relations are the degree of support in relationships among peers at work [20]. Peer communication is the basis for peer relations [24]. Quality of care is patient care that meets an individual's needs [15]. The safety of care means that the patient is not harmed in the process of receiving individualized care [1]. The hypothesized relationships between these model concepts are: (1) horizontal violence and peer relationships (communication) are inversely related and (2) peer relationships and the quality and safety of patient care are positively related.

Maslow and DeVito's respective concepts of safety needs [19] and psychological noise [10] were not measured or analyzed in this study. But in the model, they provide a potential explanation for the hypothesized inverse relationship between horizontal violence and peer relationships [24]. Maslow theorized that safety needs are a human's need to feel physically and psychologically safe [19]. When they do, they tend to interact with others; when they do not, they avoid interaction. When humans do not feel safe with one another, DeVito's [10] concept of psychological noise is a potential explanation for why they also may not communicate [24]. In 
his essential human communication model, psychological noise hinders communication. He theorized that psychological noise, at one extreme, prevents all communication because of thoughts, attitudes and feelings established in a person's mind. When a person has strong distrustful feelings or a predetermined negative idea about how communication will play out, they do not communicate.

Reason's concept of defense layers was not examined in this study but it does provide a possible explanation for how peer relationships and the quality and safety of patient care may be positively related in the model [24]. Using the Swiss cheese model of system accidents, Reason [28] theorizes that patients can be harmed in highly technical organizations, such as healthcare. He uses the concept of defense layers to explain that patients can be protected by layers that consist of people, technology, and policies and procedures that create a barrier designed to stop errors that happen within these environments from reaching patients. When these layers are jeopardized, those errors can harm patients. People are the defense layer of interest because they consist of front line caregivers, including their relationships and communication with each other. When peer relationships are not supportive, their communication decreases and so does the possibility that errors will be identified and patient harm averted.

\section{Methods}

The aims of the study were (1) to describe the association of horizontal violence, peer relations, quality of care, errors and adverse events with nurse and work characteristics and (2) to test three hypotheses drawn from the model: horizontal violence and peer relations are inversely related, horizontal violence and the quality of patient care are inversely related, horizontal violence and errors and adverse events (safety of patient care) are positively related. 


\subsection{Design}

This cross-sectional model testing study is part of a larger study, guided by the model in figure 1, that described hospital staff registered nurses' $(\mathrm{RN})$ work-related perceptions of themselves (oppressed self), nursing as a group (oppressed group), their negative behavior (horizontal violence) and relationships (peer relations) with other staff RNs, and the quality and safety of patient care [23]. The relationships between oppressed self and horizontal violence and oppressed group and horizontal violence were reported elsewhere [25]. The relationships among horizontal violence, peer relationships, and the quality and safety of patient care are reported here.

\subsection{Sample}

The targeted population was staff nurses working in hospitals, the group most likely to experience horizontal violence (negative behavior among peers). An a priori power analysis was done utilizing NQuery using a multiple linear regression model which included 6 predictors with a squared multiple correlation $\left(\mathrm{R}^{2}\right)$ of 0.13 . A sample size of 131 would have $80 \%$ power to detect an increase in $\mathrm{R}^{2}$ of 0.05 due to including 1 additional predictor in the model at $\alpha=0.05$. As reported elsewhere, the state Board of Registered Nursing mailing list provided the names and addresses of 309,940 RNs, who held active licenses in CA as of January 26, 2010 [32]. This list did not include work setting or job title. To assure that the sample drawn would include a sufficient number of hospital staff RNs, 3000 names and addresses were randomly selected from the list. The inclusion criteria were: RNs working as staff nurses in hospitals in California, who agreed to share their perceptions in an anonymous survey. 


\subsection{Data Collection}

Data were collected via a paper based or online survey between March 2010 and August 2010. The adapted version of Dillman's [9] Tailored Design used to administer the survey was fully described elsewhere [25]. In summary, nurses were contacted up to three times. The first was to invite all 3000 to participate. The second was to send them (1) an information sheet for the paper survey or the online survey, (2) a paper survey, if preferred, and (3) a $\$ 2$ bill as an incentive. The third was sent to thank them for participating or to remind them to complete the survey. Receipt of their survey by researchers signified consent.

\subsection{Measures}

The researchers used a five-part survey to collect data about: (1) horizontal violence, (2) peer relations, (3) quality of care, (4) errors and adverse events (safety of care), and (5) demographic characteristics.

\subsubsection{Horizontal Violence}

The 22 item Negative Acts Questionnaire-Revised (NAQ-R) measured horizontal violence [11]. In two prior studies, the "being exposed to an unmanageable workload" item was removed from analyses on the assumption that this item reflects work environments in general not a negative act as such $[17,25]$. This item was removed from the current study. Researchers in four studies provided evidence of reliability and validity of the 22 item measure. When used in workers outside of healthcare, Cronbach's alpha was .90 in the UK [11] and .92 in the US [18]. In studies using nursing samples, internal consistency was .89 [17] and .88 [33]. Evidence of predictive validity was provided in all four studies when associations between the NAQ-R and different concepts were hypothesized and tested $[11,17,18,33]$. Participants responded by stating how frequently they experienced each of the negative acts from another staff $\mathrm{RN}$ over the 
last six months: $1=$ never to 5=daily [25]. Mean scores ranged from 1-5, the higher the score the more frequently negative acts were experienced at work.

\subsubsection{Peer Relations}

The Nurse Staffing and the Quality of Care Questionnaire provided a four item peer relations subscale of work environment [7]. Previous work provided evidence of reliability, Cronbach's alpha .75, and factor analysis resulted in evidence of validity of the subscale [7]. Participants indicated their agreement using the following response scale: $1=$ strongly disagree to 5=strongly agree. Mean scores ranged from 1-5, the higher the score the more supportive the relationships.

\subsubsection{Quality and Safety of Patient Care}

Dependent variables in the model were quality of care and safety of care. The quality of care scale developed for this study consisted of three items: two from the Aiken et al.'s [2] Nurse-Rated Quality of Care, adapted with first author's permission, and the third item from the Hospital Survey on Patient Safety Culture [1]. Participants assigned a grade to each item: 1=F, failing to 5=A, excellent. Mean scores ranged from 1-5, the higher the score the higher the perceived quality of patient care.

Patient safety was conceptualized as a set of events, irrespective of whether or not patient injury results [1] that may have been experienced by a patient or nurse in the past six months. Events included errors, defined as an intervention or plan that did not meet the desired goal, and adverse events, defined as an injury caused by care delivered [15]. The errors and adverse events scale developed for this study included six items: four taken from the Aiken et al.'s [3] measure of negative events and two new items. The response scale ranged from: $1=$ never to 
$4=$ frequently. Mean scores ranged from 1-4, the higher the score the more often nurses or their patients experienced errors and adverse events in the last six months.

\subsubsection{Demographics}

'Fill in the blank items' were used to collect data about participants' age in years, number of years working as an RN in a hospital, and the average number of hours worked per week. Multiple choice items collected data about gender, race, basic RN education, highest degree held, type of hospital, size of hospital, and clinical area [25]. Choices for type of hospital included community-based, teaching, non-teaching, and government/federal/military/VA type. Among the 16 clinical area options were critical care, medical/surgical, obstetrics, pediatrics, perioperative/post-anesthesia, mental health, and one fill in the black marked “other." Reported clinical areas were categorized to intensive care, non-intensive care, and other. This three group clinical area variable was dummy coded using intensive care for the omitted reference group.

\subsection{Ethical Considerations}

A university ethics committee approved this study. The researchers ensured the confidentiality of participant identities on the paper and online survey formats. The information sheet listed statements intended to minimize participants' potential discomfort as they recalled their thoughts and feelings on the study topic.

\subsection{Data Analysis}

The Statistical Package for the Social Sciences (SPSS) version 16.0 for Windows (2007) (SPSS Inc., Chicago, IL) was used for data analysis. Descriptive statistics were calculated to determine sample characteristics. Percentage described the incidence of horizontal violence. Cronbach's alpha measured the internal consistency of each scale. Mean scores for the 21 item NAQ-R scale, peer relations subscale, the quality of patient care scale, and errors and adverse 
event scale were calculated. Pearson $r$ and hierarchical multiple regression analyses were used to test the hypotheses. Alpha was preset at .05 .

\section{Results}

The researchers mailed 3000 postcards and 234 nurses replied asking for a survey [25]. Nineteen persons were not eligible, so 215 received surveys in return. The researchers received 175 completed surveys: 84 on paper and 91 online. The response rate to this study was calculated as $18.8 \%$ [25].

\subsection{Sample Characteristics}

Participants were a mean age of 46.3 years $(\mathrm{SD}=12.36)$, female $(\mathrm{n}=159 ; 91 \%)$, Caucasian $(\mathrm{n}=107 ; 61 \%)$, and their basic $\mathrm{RN}$ education was an associate degree $(\mathrm{n}=71 ; 41 \%)$. The largest percentage worked on medical-surgical units $(n=36 ; 21 \%)$ and an average of 35.6 hours per week ( $\mathrm{SD}=9.02)$. Experience working as an $\mathrm{RN}$ in a hospital averaged 16.0 years $(\mathrm{SD}=12.18)$. Most worked in 100-300 bed hospitals ( $\mathrm{n}=84,48 \%)$ and in community-based hospitals $(\mathrm{n}=114,65.1 \%)$. Additional demographic findings were male $(\mathrm{n}=13 ; 7 \%)$, Asian, not Filipino or Indian $(n=20: 11.4 \%)$, Filipino $(n=15 ; 9 \%)$, Hispanic $(n=13 ; 7 \%)$, mixed race $(n=10 ; 6 \%)$, and Black ( $\mathrm{n}=8 ; 5 \%)$. Other levels of basic RN education were Bachelor's degree ( $\mathrm{n}=70 ; 40 \%)$, Diploma $(\mathrm{n}=18 ; 10 \%)$, second degree/accelerated $(\mathrm{n}=9 ; 5 \%)$, and master's degree $(\mathrm{n}=5 ; 3 \%)$.

The Cronbach's alpha values for the 21 item NAQ-R, quality of care scale, and the error and adverse events scale were strong (.87-.92) (Table 1).

\subsection{Incidence}

While most of the nurses experienced horizontal violence, fewer experienced it regularly. Nearly eight of ten nurse participants $(79.4 \% ; \mathrm{n}=139)$ reported experiencing horizontal violence at work at least once during the six months preceding the study. The majority $(58.3 \%$; $\mathrm{n}=102)$ 
reported experiencing horizontal violence now and then and monthly while $21.1 \%(n=37)$ reported being subjected to it weekly and daily.

\subsection{Mean Score Differences of Nurse and Work Characteristics by Research Variable}

There were only two differences in reported horizontal violence by nurse or hospital characteristics [Tables 1 and 2]. The frequency of horizontal violence was reported as higher by nurses who did not have a Bachelor of Science in Nursing degree $(\mathrm{BSN})$ as basic education $(\mathrm{p}<$ $.05)$ and by those working in clinical areas other than intensive care and medical/surgical units ( $\mathrm{p}$ $<.01)$. There were no statistically significant differences in horizontal violence based on gender, race, type or size of hospital, age, experience, or working hours.

Scores on the peer relations scale and the quality of care scale were not related to any of the nurse demographic variables. However, nurses working in teaching hospitals reported a significantly $(\mathrm{p}<.05)$ higher quality of care. Nurses without BSN preparation, older nurses, and those working on units other than intensive care and medical/surgical units reported significantly more errors and adverse events $(\mathrm{p}<.01)$.

\subsection{Hypothesis Testing}

Based on bivariate relationship findings (Tables $1 \& 2$ ), variables included in the multivariate regressions were age, basic RN education, teaching hospital, and clinical area.

\section{Hypothesis 1: Horizontal violence and peer relations are inversely related}

The researchers found a statistically significant inverse correlation between horizontal violence and peer relations $(\mathrm{r}=-.640 ; \mathrm{p}<.01$, Table 2$)$. In multivariate regression analysis, horizontal violence was the only significant predictor of peer relations (Table 3). For every one unit increase in horizontal violence score, there was a corresponding 1.084 decrease in peer relations score, controlling for the other variables $(\mathrm{p}<.05)$. 
Hypothesis 2: Horizontal violence and the quality of patient care are inversely related. Horizontal violence and the quality of patient care were inversely related $(r=-.469 ; p<.01$, Table 2). In the multivariate regression analysis, only horizontal violence and clinical area predicted the quality of patient care (Table 3). Comparing non-intensive care clinical areas to intensive care, there was a corresponding .210 decrease in the quality patient care score, controlling for the other variables $(\mathrm{p}<.05)$. For every one unit increase in horizontal violence score, there was a corresponding .672 decrease in the quality of patient care score, controlling for the other variables $(\mathrm{p}<.05)$. The significant negative coefficient for horizontal violence on quality in Model One was reduced and clinical area became insignificant when the peer relations variable was added in Model Two.

\section{Hypothesis 3: Horizontal violence and errors and adverse events are positively related.}

Horizontal violence and errors and adverse events were positively correlated $(\mathrm{r}=.442 ; \mathrm{p}<.01$, Table 2). In the multivariate regression analysis, horizontal violence and clinical area were significant predictors of errors and adverse events (Table 3). Comparing other clinical areas to intensive care, there was a corresponding .359 increase in the errors and adverse events score, controlling for the other variables $(\mathrm{p}<.05)$. For every one unit increase in horizontal violence score, there was a corresponding .428 increase in errors and adverse events score, controlling for the other variables $(\mathrm{p}<.05)$. When peer relations was added in Model Two, there was no reduction in the significance of horizontal violence and a minimal reduction in clinical area on errors and adverse events, suggesting that peer relations does not modify the relationship between horizontal violence or clinical area and errors and adverse events. 


\section{Discussion}

This study produced new knowledge about the relationships between horizontal violence among nurses in hospitals, their relationships with each other and the safety and quality of patient care. In sections that follow, we suggest possible explanations for these relationships, discuss practice implications and future research, and identify study limitations.

\subsection{Horizontal Violence and Peer Relationships}

The researchers found that horizontal violence and peer relationships were related in the predicted direction. That is, horizontal violence was higher for those who scored lower on peer relations. These results provide evidence to support the theoretical model for this study as well as previous literature that horizontal violence strains peer relationships [32]. The model provides one potential explanation for this relationship. Nurses who have been subjected to horizontal violence may perceive threats to their psychological well-being (safety needs) and have predetermined negative beliefs about how communication exchanges will occur (psychological noise) may not relate or communicate with their peers [24]. This relationship should be tested with other populations of hospital staff RNs.

\subsection{Horizontal Violence and Quality and Safety of Patient Care}

Both the second and third hypotheses were supported: as horizontal violence increased, the quality of care decreased and errors and adverse events increased. These results provide evidence to support the theoretical model for this study as well as suggestions in previous literature that patient care is affected by horizontal violence in hospitals [21, 32]. The model provides one possible explanation for this relationship. When nurses do not relate to one another, including maintaining open communication, the integrity of the protective defense layer is jeopardized placing patients at risk for harm [24]. 
The particularly striking finding was that when peer relations was added in the final step of the hierarchical regression model, it reduced the significance of the relationship between horizontal violence and the quality of patient care but not for errors and adverse events. This suggests that peer relations provides information about how horizontal violence can impact (or not) the quality and safety of patient care. In contrast, peer relations did not have the same effect on the relationship between horizontal violence and errors and adverse events. This finding is inconsistent with current thought that inadequate communication is linked with $60 \%$ of real or potential harm to patients receiving care in healthcare institutions [37]. More research is needed to examine this relationship in other populations of hospital staff RNs to gather evidence of its existence in more than one study.

\subsection{Implications for Practice}

This study adds to our concerns about horizontal violence by emphasizing the potential effects on patient care as well as showing how it occurs to most nurses regardless of their experience or personal characteristics. To mitigate this effect, hospital staff RNs should focus on fostering supportive peer relationships at work. A key component of this focus should be for nurses to determine if horizontal violence occurs at their hospital and, if so, acknowledge its presence and possible impact on patient care. Once determined, nurses should begin to discuss the state of their peer relationships and, if necessary, adopt an initiative to improve the degree of support in them. Nurse managers should support staff nurses seeking to embrace such an initiative in the interest of patient care.

\subsection{Future Research}

The association among horizontal violence, peer relationships, and the quality and safety of patient care should be tested further. If the relationship continues to be supported, the current 
gap regarding what contributes to these relationships remains. Safety needs, psychological noise, and defense layers were not examined in this study but they did provide an explanation for the link between examined concepts. Future research should describe the relationship among horizontal violence, safety needs, psychological noise, peer relationships, defense layers and the quality and safety of patient care. Growing evidence of empirical links, or lack of them, validates and offers opportunity for improvement of the model used to guide this study [24]. Mounting empirical evidence of related concepts provides support for intervention studies to minimize the impact of horizontal violence on patient care [24].

\subsection{Limitations}

The study had several limitations. First the response rate was low and produced a small sample, although large enough to exceed the power analysis recommendations. Whether there was a self-selection bias in that those who participated may have more experiences with horizontal violence than those who did not participate cannot be determined; but, the basic rate of horizontal violence, the proportion of respondents experience negative acts weekly or daily (21\%), was nearly the same as previous studies $[17,33]$. Comparing the study sample to a recent study of California nurses, [36], this sample was representative with regard to age, gender, race, basic RN education, clinical area, and average number of hours worked per week. However, participants were predominately Caucasian and female possibly skewing findings toward that group. In this cross-sectional study, the causal direction of effects between the concepts analyzed cannot be certain. However, there is evidence of predictive validity of the measures since the relationships among variables were as predicted. In addition, the Cronbach's alpha values for the 21 item NAQ-R, quality of care scale, and the error and adverse events scale were strong (.8792) but calculated for the first time in this study, so no comparison across studies could be made. 
Similar to Blegen et al.'s [7] study, the reliability of the peer relations scale in this study was good (.76), building on evidence of good reliability in a different study population.

\section{Conclusion}

This study produced new knowledge about the relationship between horizontal violence among nurses in hospitals, their relationships with each other and the safety and quality of patient care. Nurses who experienced horizontal violence perceived less supportive relationships with peers, lower quality of care, and higher frequency of errors and adverse events. To mitigate the impact of horizontal violence on the quality and safety of patient care, supportive peer relationships need to be fostered and maintained. More research is needed on a global scale to gather evidence of these relationships in populations of hospital staff RNs. 


\section{Acknowledgements}

This research was funded by the University of California, San Francisco (UCSF) School of Nursing's Center for Patient Safety and Century Club Funds, UCSF Graduate Division’s Graduate Student Research Award, and Sigma Theta Tau International Alpha Eta Chapter Research Award. The first author wishes to thank the Gordon and Betty Moore Foundation for the Betty Irene Moore Doctoral Fellowship. The authors express their gratitude to the nurses who gave their time and participated in this study. 


\section{References}

[1] Agency for Healthcare Research and Quality [homepage on the Internet]. Rockville, MD: Agency for Healthcare Research and Quality; 2004 [cited 2012 Aug 30]. Hospital Survey on Patient Safety Culture; [about two screens]. http://www.ahrq.gov/qual/patientsafetyculture/hospscanform.pdf

[2] Aiken LH, Clarke SP, Sloan DM. Hospital staffing, organization, and quality of care: crossnational findings. Int J Qual Health Care. 2002; 14(1): 5-13.

[3] Aiken LH, Clarke SP, Xue Y, Sloane DM. Supplemental nurse staffing in hospitals and quality of care. J Nurs Adm. 2007; 37(7/8): 335-342.

[4] Ashley J. Hospitals, paternalism, and the role of the nurse. New York: Teachers College Press; 1976.

[5] Baldwin DC, Daugherty SR. Interprofessional conflict and medical errors: results of a national multi-specialty survey of hospital residents in the US. J Interprof Care 2008; 22(6): 573-586.

[6] Blanton BA, Lybecker C, Spring NM. A horizontal violence position statement [Internet]. 1998. [cited 2012 Aug 30]. Available from http://proactivenurse.com/index.php?option=com_content\&Itemid=22\&id=83.

[7] Blegen MA, Vaughn T, Pepper G, Vojir C, Stratton K, Boyd M, Armstrong G. Patient and staff safety: voluntary reporting. Am J of Med Qual. 2004; 19(2): 67-74.

[8] DeMarco R, Roberts SJ, Norris A, McCurry MK. The development of the nurse workplace scale: Self-advocating behaviors and beliefs in the professional workplace. J Prof Nurs. 2008; 24(5): 296-301. 
[9] Dillman D. Mail and Internet Surveys the Tailored Design Method. $2^{\text {nd }}$ ed. Hoboken (NJ): Wiley; 2007.

[10] DeVito JA. Essentials of Human Communication. $6^{\text {th }}$ ed. Boston: Pearson Allyn and Bacon; 2008.

[11] Einarsen S, Hoel H, Notelaers G. Measuring exposure to bullying and harassment at work: validity, factor structure and psychometric properties of the negative acts questionnairerevised. Work \& Stress. 2009; 23(1): 24-44.

[12] Farrell GA. Aggression in clinical settings: nurses' views - a follow up study. J Adv Nur. 1999; 29(3): 532-541.

[13] Freire P. Pedagogy of the oppressed. $30^{\text {th }}$ anniversary ed. New York: The Continuum International Publishing Group; 2003, original work published 1970.

[14] Garman AN, Leach DC, Spector N. Worldviews in collision: conflict and collaboration across professional lines. J Organ Behav. 2006; 27: 829-849.

[15] Institute of Medicine. Crossing the quality chasm: A new health system for the $21^{\text {st }}$ century. Washington DC: National Academy Press; 2001.

[16] Institute of Medicine. Keeping patients safe: transforming the work environment of nurses. Washington DC: National Academy Press; 2004.

[17] Johnson SL, Rea RE. Workplace bullying concerns for nurse leaders. J Nurs Adm. 2009; 39(2): 84-90.

[18] Lutgen-Sandvik P, Tracy SJ, Alberts JK. Burned by bullying in the workplace: prevalence, perception, degree and impact. Journal of Management Studies. 2007; 44(6): 837-861. [19] Maslow AH. A theory of human motivation. Psychol Rev. 1943; 50(4): 370-396. 
[20] McCloskey J.C. Two requirements for job contentment: autonomy and social integration. J Nurs Scholarsh. 1990; 22(3): 140-143.

[21] McKenna BG, Smith NA, Poole SJ, Coverdale JH. Horizontal violence: experiences of registered nurses in their first year of practice. J Adv Nurs. 2003; 42(1): 90-96.

[22] Nielsen MB, Skogstad A, Matthiesen SB, Glas L, Aasland MS, Notelaers G, Einarsen S. Prevalence of workplace bullying in Norway: comparisons across time and estimation methods. European Journal of Work and Organizational Psychology. 2009; 18(1): 81101.

[23] Purpora C. Horizontal violence among hospital staff nurses and the quality and safety of patient care. Ph.D. University of California San Francisco.

[24] Purpora C, Blegen MA. Horizontal violence and the quality and safety of patient care: A conceptual model. Nurs Res Pract. 2012: 5 pages. doi: 10.1155/2012/306948.

[25] Purpora C, Blegen MA, Stotts NA. Horizontal violence between hospital staff nurses related to oppressed self or oppressed group. J Prof Nurs. 2012; 28(5): 306-314.

[26] Quine L. Workplace bullying in nurses. J Health Psychol. 2001; 6(1): 73-84.

[27] Quine L. Workplace bullying, psychological distress, and job satisfaction in junior doctors. Quarterly of Healthcare Ethics. 2003; 12: 91-101.

[28] Reason J. Human error: models and management. BMJ. 2000; 320: 768-770.

[29] Reverby SM. Ordered to care: The dilemma of American Nursing, 1850-1945. New York: Cambridge University Press; 1987.

[30] Roberts SJ. Oppressed group behavior: implications for nursing practice. ANS Adv Nurs Sci. 1983; 5(4): 21-30. 
[31] Rosenstein AH, O'Daniel M. A survey of the impact of disruptive behaviors and communication defects on patient safety. Jt Comm J Qual Patient Saf. 2008; 34(8): 464471.

[32] Rowe MM, Sherlock HS. Stress and verbal abuse in nursing: Do burned out nurses eat their young? J Nurs Manag. 2005; 13: 242-248.

[33] Simons S. Workplace bullying experienced by Massachusetts registered nurses and the relationship to intention to leave the organization. ANS Adv Nurs Sci. 2008; 31(2): E48E59.

[34] Skillings LN. Perceptions and feelings of nurses about horizontal violence as an expression of oppressed group behavior. In Thompson JL, Allen DG, Rodrigues-Fisher L, editors. Critique, resistance, and action. New York: National League for Nursing Press; 1992.

[35] Sofield L, Salmond SW. Workplace violence: a focus on verbal abuse and intent to leave the organization. Orthop Nurs. 2003; 22(4): 274-283.

[36] Spetz J, Keane D, Herrera C. California board of registered nursing 2008 survey of registered nursing. San Francisco: University of California, San Francisco School of Nursing and Center for the Health Professions; 2009.

[37] The Joint Commission. Sentinel event data: Root causes by event type 2004-third quarter2011 [Internet]. Oakbrook Terrace, IL: The Joint Commission, 2011 [cite 2012 Aug 30]. Available from: http://www.jointcommission.org/assets/1/18/Root_Causes_Event_Type_20043Q2011.pdf.

[38] Vessey JA, DeMarco RF, Gaffney DA, Budin WC. Bullying of staff registered nurses in the workplace: a preliminary study for developing personal and organizational strategies for 
transforming of hostile to health workplace environments. J Prof Nurs. 2009; 25(5): 299306.

[39] Whitaker T. Social workers and workplace bullying: Perceptions, responses and implications. WORK. 2012; 42(1): 115-123. 
Table 1

Mean Score Differences of Nurse or Work Characteristics by Research Variable and Reliability of Measures

\begin{tabular}{|c|c|c|c|c|}
\hline & $\begin{array}{l}\text { Horizontal } \\
\text { Violence } \\
21 \text { items }\end{array}$ & $\begin{array}{l}\text { Peer } \\
\text { Relations } \\
4 \text { items }\end{array}$ & $\begin{array}{l}\text { Quality of } \\
\text { Care } \\
3 \text { items }\end{array}$ & $\begin{array}{l}\text { Errors } \\
\text { Adverse } \\
\text { Events } \\
6 \text { items }\end{array}$ \\
\hline Overall Mean (SD) & $1.52(.525)$ & $4.07(.872)$ & $3.99(.712)$ & $1.75(.585)$ \\
\hline Cronbach's alpha & .92 & .76 & .89 & .87 \\
\hline $\begin{array}{l}\text { Gender } \\
\text { Female }(n=159) \\
\text { Male }(n=13)\end{array}$ & $\begin{array}{l}1.52 \\
1.48\end{array}$ & $\begin{array}{l}4.08 \\
3.83\end{array}$ & $\begin{array}{l}3.98 \\
3.92\end{array}$ & $\begin{array}{l}1.74 \\
1.92\end{array}$ \\
\hline $\begin{array}{l}\text { Race } \\
\text { Caucasian }(n=107) \\
\text { Non-Caucasian }(n=66)\end{array}$ & $\begin{array}{l}1.52 \\
1.50\end{array}$ & $\begin{array}{l}4.11 \\
3.99\end{array}$ & $\begin{array}{l}4.03 \\
3.90\end{array}$ & $\begin{array}{l}1.72 \\
1.81\end{array}$ \\
\hline $\begin{array}{l}\text { Basic RN Education } \\
\text { Non-BSN }(n=89) \\
\text { BSN or }>(n=84)\end{array}$ & $\begin{array}{l}1.60^{*} \\
1.42\end{array}$ & $\begin{array}{l}3.98 \\
4.15\end{array}$ & $\begin{array}{l}3.92 \\
4.05\end{array}$ & $\begin{array}{l}1.89 * * \\
1.61\end{array}$ \\
\hline $\begin{array}{l}\text { Type of Hospital: } \\
\text { Community } \\
\text { Yes }(n=114) \\
\text { No }(n=58)\end{array}$ & $\begin{array}{l}1.53 \\
1.48\end{array}$ & $\begin{array}{l}4.04 \\
4.12\end{array}$ & $\begin{array}{l}3.93 \\
4.07\end{array}$ & $\begin{array}{l}1.79 \\
1.70\end{array}$ \\
\hline $\begin{array}{l}\text { Teaching } \\
\text { Yes }(n=66) \\
\text { No }(n=106)\end{array}$ & $\begin{array}{l}1.50 \\
1.53\end{array}$ & $\begin{array}{l}4.20 \\
3.98\end{array}$ & $\begin{array}{l}4.12 * \\
3.89\end{array}$ & $\begin{array}{l}1.69 \\
1.80\end{array}$ \\
\hline $\begin{array}{l}\text { Government } \\
\text { Yes }(n=7) \\
\text { No }(n=165)\end{array}$ & $\begin{array}{l}1.54 \\
1.51\end{array}$ & $\begin{array}{l}3.75 \\
4.08\end{array}$ & $\begin{array}{l}3.71 \\
3.99\end{array}$ & $\begin{array}{l}1.94 \\
1.75\end{array}$ \\
\hline $\begin{array}{l}\text { Size of Hospital } \\
<100(\mathrm{n}=20) \\
100-300(\mathrm{n}=84) \\
>300(\mathrm{n}=65)\end{array}$ & $\begin{array}{l}1.67 \\
1.50 \\
1.50\end{array}$ & $\begin{array}{l}4.08 \\
4.07 \\
4.06\end{array}$ & $\begin{array}{l}3.83 \\
3.95 \\
4.06\end{array}$ & $\begin{array}{l}1.94 \\
1.81 \\
1.62\end{array}$ \\
\hline $\begin{array}{l}\text { Clinical Area } \\
\text { Intensive Care }(n=69) \\
\text { Non-intensive Care }(n=79) \\
\text { Other }(n=22)\end{array}$ & $\begin{array}{l}1.63 \\
1.38 \\
1.66 * * \\
\end{array}$ & $\begin{array}{l}4.07 \\
4.16 \\
3.72 \\
\end{array}$ & $\begin{array}{l}4.05 \\
4.00 \\
3.76 \\
\end{array}$ & $\begin{array}{l}1.72 \\
1.67 \\
2.15^{* *} \\
\end{array}$ \\
\hline
\end{tabular}

Note: We previously reported the data in the horizontal violence column [32].

Note: Clinical Area: Intensive care (e.g. critical care, step down, telemetry), non-intensive care (e.g. medical surgical, pediatrics, oncology), other (mental health, geriatrics, worked in multiple areas did not specialize). ${ }^{*}$ Difference across group statistically significant $* \mathrm{p}<.05 ; * * \mathrm{p}<.01$ 
Table 2

Correlation of HV, Peer Relations, Quality of Care, and Errors and Adverse Events With Age, Years of Experience Working as an RN in the Hospital, and Average Number of Hours Worked per Week.

\begin{tabular}{|c|c|c|c|c|c|c|c|}
\hline Variable & $\begin{array}{l}\text { Horizontal } \\
\text { Violence }\end{array}$ & $\begin{array}{l}\text { Peer } \\
\text { Relations }\end{array}$ & $\begin{array}{l}\text { Quality of } \\
\text { Care }\end{array}$ & $\begin{array}{l}\text { Errors } \\
\text { Adverse } \\
\text { Events }\end{array}$ & Age & Years & Hours \\
\hline $\begin{array}{l}\text { Horizontal } \\
\text { Violence }\end{array}$ & 1.0 & & & & & & \\
\hline $\begin{array}{l}\text { Peer } \\
\text { Relations }\end{array}$ & $-.640 * *$ & 1.0 & & & & & \\
\hline $\begin{array}{l}\text { Quality } \\
\text { Safety }\end{array}$ & $-.469 * *$ & $.615^{* *}$ & 1.0 & & & & \\
\hline $\begin{array}{l}\text { Adverse } \\
\text { Events }\end{array}$ & $.442 * *$ & $-.333 * *$ & $-.328 * *$ & 1.0 & & & \\
\hline Age & .153 & -.063 & -.133 & $.214^{* *}$ & 1.0 & & \\
\hline Years & .085 & -.009 & -.111 & .116 & $.776^{* *}$ & 1.0 & \\
\hline Hours & .124 & -.088 & .004 & .072 & .011 & -.070 & 1.0 \\
\hline
\end{tabular}


Table 3

Hierarchical Multiple Regression Analyses for Variables Predicting Peer Relations, Quality of Care, and Errors and Adverse Events

\begin{tabular}{|c|c|c|c|c|c|}
\hline $\begin{array}{l}\text { Dependent } \\
\text { Variable }\end{array}$ & $\begin{array}{l}\text { Peer } \\
\text { Relations }\end{array}$ & $\begin{array}{l}\text { Quality of } \\
\text { Care } \\
\text { Model } 1\end{array}$ & $\begin{array}{l}\text { Quality of } \\
\text { Care } \\
\text { Model } 2\end{array}$ & $\begin{array}{c}\text { Errors and } \\
\text { Adverse Events } \\
\text { Model } 1\end{array}$ & $\begin{array}{c}\text { Errors and } \\
\text { Adverse Events } \\
\text { Model } 2\end{array}$ \\
\hline Age of nurse & .005 & .000 & -.002 & .004 & .005 \\
\hline $\begin{array}{l}\text { Basic RN } \\
\text { education }\end{array}$ & -.028 & -.023 & -.012 & -.108 & -.110 \\
\hline $\begin{array}{l}\text { Teaching } \\
\text { hospital }\end{array}$ & .154 & .175 & .117 & -.051 & -.043 \\
\hline \multicolumn{6}{|l|}{$\begin{array}{l}\text { Clinical Area } \\
\text { (Intensive care } \\
\text { omitted) }\end{array}$} \\
\hline $\begin{array}{l}\text { Non-intensive } \\
\text { care }\end{array}$ & -.138 & $-.210^{*}$ & -.158 & .068 & .061 \\
\hline Other & -.333 & -.239 & -.114 & $.359 * *$ & $.342 *$ \\
\hline $\begin{array}{l}\text { Horizontal } \\
\text { Violence }\end{array}$ & $-1.084 * *$ & $-.672 * *$ & $-.265^{*}$ & $.428 * *$ & $.373 * *$ \\
\hline Peer Relations & & & $.376 * *$ & & -.051 \\
\hline Model p & .000 & .000 & .000 & .000 & .396 \\
\hline $\mathrm{R}^{2}$ & .442 & .281 & .404 & .264 & .268 \\
\hline
\end{tabular}

Note: Unstandardized coefficients reported. Clinical Area: Intensive care (e.g. critical care, step down, telemetry), non-intensive care (e.g. medical surgical, pediatrics, oncology), other (mental health, geriatrics, worked in multiple areas did not specialize)

$* \mathrm{p}<.05 . * * \mathrm{p}<.01$. 


\section{Figure 1}

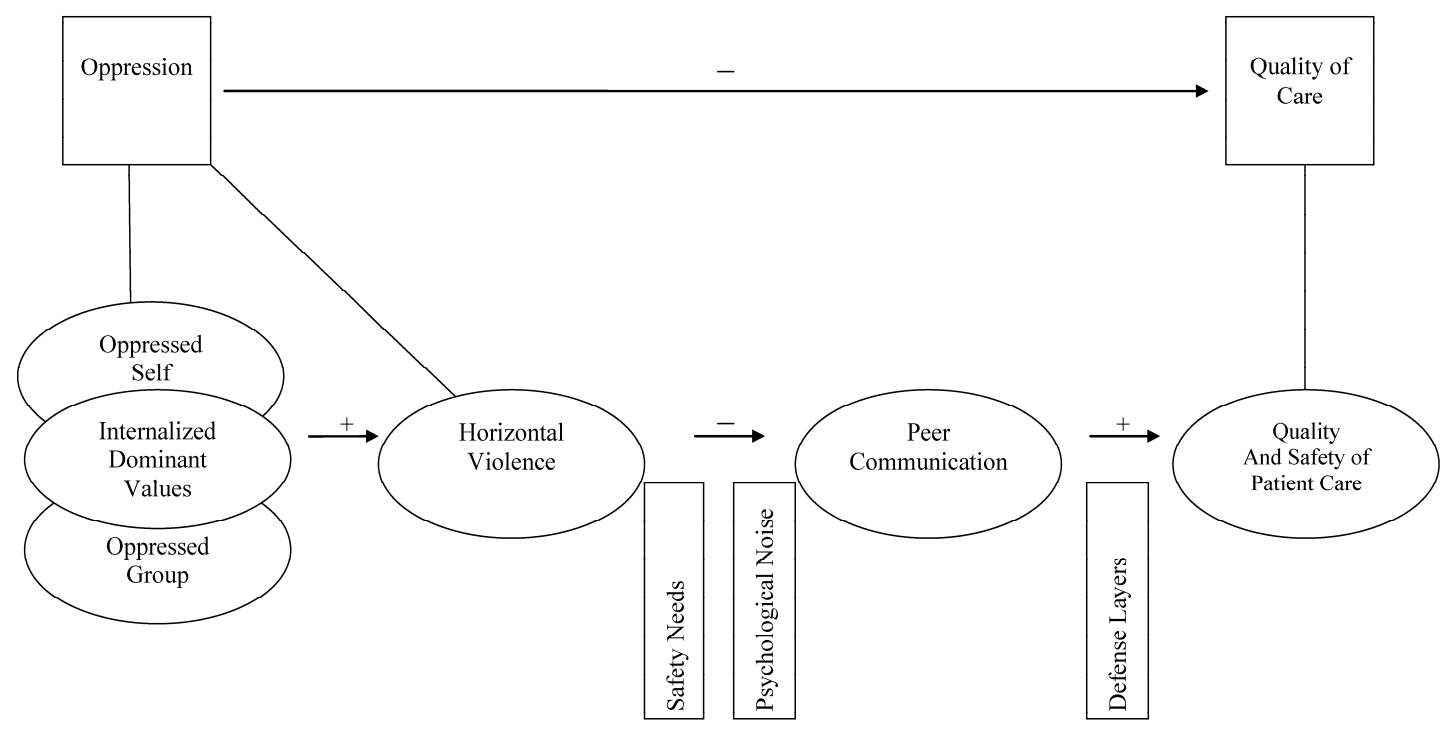

Figure 1. A Conceptual Model for Horizontal Violence and the Quality and Safety of Patient Care. Reprinted from the Journal of Professional Nursing, 28/5, Purpora C, Blegen MA, Stotts NA, Horizontal Violence Among Hospital Staff Nurses Related to Oppressed Self or Oppressed Group, 9, 2012, with permission from Elsevier. 